\title{
An Investigation and Analysis of Information Overload in Manager's Work
}

\author{
Tao $\mathrm{Li}^{1},{\mathrm{Min} \mathrm{Li}^{2}}^{2}$ \\ ${ }^{1}$ Department of Social Science, Air Force College in Xuzhou, Xuzhou, China; ${ }^{2}$ School of Economics and Management, Nanjing \\ University of Aeronautics and Astronautics, Nanjing, China. \\ Email: f22xz@sohu.com.
}

Received November $6^{\text {th }}, 2010$; revised December $23^{\text {rd }}, 2010$; accepted December $28^{\text {th }}, 2010$.

\begin{abstract}
The problem of information overload in management field has been receiving increasing attention, while there are less empirical researches now. This paper proposes a conceptual model and some operational variables, in which information overload is as an intervening variable between the factors of causes and impacts. An investigation and analysis has been conducted from a selected sample of managers. This research suggests that work efficiency and work quality are both not strongly connected with information overload. We also find that the main causes of information overload are the work interruption and work time pressure but the amount of information.
\end{abstract}

Keywords: Information Overload, Investigation, Analysis, Manager's Work

\section{Introduction}

Information overload is at first a term popularized by Alvin Toffler that refers to the difficulty a person can have understanding an issue and making decisions that can be caused by the presence of too much information. Alvin Toffler cautioned us and pointed to research on information overload on human behavior [1]. The studies of information overload begun from the early days of century twenty and increased from 1960's. More recently, the topic has been linked with the rapid development of the Internet usage and the information explosion in the amount of data.

Although the information overload is being focused in management circle and other fields, therefore, up to now, mainly researches of information overload are commonsense assumptions, such as Klapp's work [2]. Most of researchers stress a negative phenomenon that should suppress or eliminated. The developments to deal with performance of computer tools to deal with performance problems supposedly caused by information overload has been a common subject in management field, yet careful research investigations of issues related to information overload have been limited.

The authors provide here an overview of information overload and its causes, from a work process centered point of view, by summarizing previous research findings through a concept causal model. This research then investigates the model to discuss the factors which may give rise to information overload, and the impacts of information overload on work efficiency and quality.

\section{The Causes and Impacts of Information Overload}

\subsection{The Concept of Information Overload}

In ordinary language, the term information overload is often used to convey the simple notion of receiving too much information. Within the research community, this everyday use of the term has led to various synonyms, and related terms, such as cognitive overload, sensory overload, communication overload, and knowledge overload information which brings out the fatigue syndrome [3]. These constructs have been applied to a variety of situations, ranging from business consulting, management meetings and the related contexts, in which information overload has been discussed in much management-related academic literature [4]. In the organizational context, frequently the described symptoms of information overload on the individual level are a general lack of perspective, cognitive strain and stress, lower job satisfaction, and the inability to use information to make a suitable decision [5]. The authors in this study hold that information overload refers to the phenomena of anxiety and fatigue, while the information over the individual capability to deal with. 


\subsection{Causes of Information Overload}

Some researchers hold that there are several variables involved from a work process-centered view. Information overload depends on the nature of work accomplished through a process and one of the most important being the work complexity in Casey's study [6]. Some researcher focus on the reason in the succession process, Schneider once points out that the information overload comes from interruption [7]. Information overload seems definitely connected with the amount and nature of knowledge and skills which are possessed by processing speed and quality and therefore they influence information overload. Apart from the work factors, some studies show that the person and his or her attitude, qualification, and experience are another important factor. While earlier studies simply state that a person's capacity to process information is limited, more recent studies include specific limiting factors such as personal skills. The level of knowledge and skill coming form experience and personal traits thus directly affects the capacity to receive information [8]. On the other hand, the decision style of a team member can affect how efficiently information is processed in Glazer's point of view [9].

\subsection{Impacts of Information Overload}

The explosive development of information and related communication technologies has brought into focus the problems of information overload. People find it ever more difficult to cope with more information they receive, and increasingly unpredictable side-effects of their actions. The longer people are subjected to information overload, the more negative its effects on physical and mental well-being. A world-wide survey found that two thirds of managers suffer from increased tension and one third from ill health because of information overload. Many academics, corporate decision-makers, and policy-makers have realized the magnitude and growing impact of the phenomenon of information overload. Most of study stresses a negative phenomenon that should be hold back or eliminated [10]. A task accomplished through a process is affected by the information overload experienced by process team member. Meglio believes that the concentration and speed should be influenced by information overload and lead to negative results [11], and information overload is surely an unfavorable factor of both work efficiency and quality.

\subsection{Conceptual Model}

Based on the above-mentioned discussions, for our part, information overload means the phenomena of sick and psychological anxiety when information over the capacity of individual process. In view of individual and work dimensions which cause the information overload, Figure 1 gives a causal model that integrates individual and work factors affecting information overload, and describes its impact on work efficiency and quality. This conceptual model incorporates the process assumptions and information overload views while the variable information overload acts as an intervening variable that mediates the influence of individual and work-related variables on work efficiency and work quality. Accordingly, it can be investigated that which factors cause the information overload and, does information overload significantly affect work efficiency and work quality?

\section{Data and Method}

This study was base on qualitative and quantitative research data collected from a sample of twenty nine of a managers training class. All people who were asked to answer a questionnaire designed by us in the sample have worked at least for over five years with management occupation, which could depict the common trait in the work process.

The data collection instrument was designed to include measures for each of the factors discussed in Figure 1, as well as open-ended questions in which the respondents have been asked. Enough indications and time should be prepared before the questionnaires are filled in.

The first three factors, Knowledge and skill, Decision

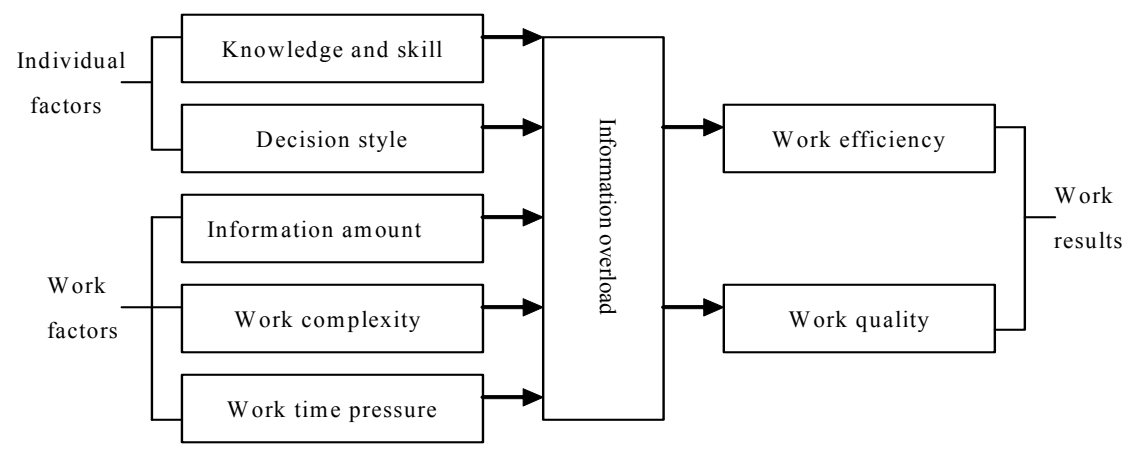

Figure 1. Causes and impacts of Information overload. 
Table 1. Respondents' trade distribution.

\begin{tabular}{cc}
\hline Trade & Respondents \\
\hline Financial & 6 \\
Education & 7 \\
Energy & 2 \\
Transportation & 2 \\
Construction & 3 \\
Communication & 4 \\
Storage & 3 \\
Others & 2 \\
Total & 29 \\
\hline
\end{tabular}

amount, Decision scope belong to the individual aspect. Paper read, Paper written, Web info absorbing, Web info transmitting, Work scope, Work interruption, Work time pressure belong to work aspect. Knowledge and skill refers to formal training days in one year. Decision amount and Work interruption mean the related times which happen in a work day. Paper read, Paper written, Web info absorbing and Web info transmitting are surveyed based on average pages in a work day. Information overload refers to the degree of individual perception.

Based on the different factors, two kinds of measurement are given. Decision scope, Decision scope, Work time pressure, Information overload, work efficiency and work quality, the six survey items were measured along a five-point Likert usage scale.

The questionnaire data were analyzed with the aim of establishing the existence and comparative strength of links between individual and work factors and perceived information overload, as well as between perceived information overload and its impact on work efficiency and work quality. This was attained by the calculation of both descriptive statistics for each of the measurement items, and the Spearman correlation coefficient. The data were analyzed by SPSS.

\section{Results and Analysis}

The correlation coefficients measure the relationship between different variables through degree of the association which this research investigated. The result can be found in line twelfth and line thirteenth in Table 2 that Spearman correlation coefficients are 0.16 and -0.21 between perceived information overload and its impacts on work efficiency and work quality. This result means there is no statistical significance of the test has been affected. Yet both in line eleventh, the result can be found the statistical significance have been tested between the information overload with the work time pressure $r_{s}=0.82, P<0.01$, and with the work interruption $r_{s}$ $=0.65, \mathrm{P}<0.01$. Apart from the two items, there is no other factor has strong relation with information overload in our investigation.

\section{Conclusions}

The results and analysis suggest a negative answer to

Table 2. Descriptive statistics for measurement factors.

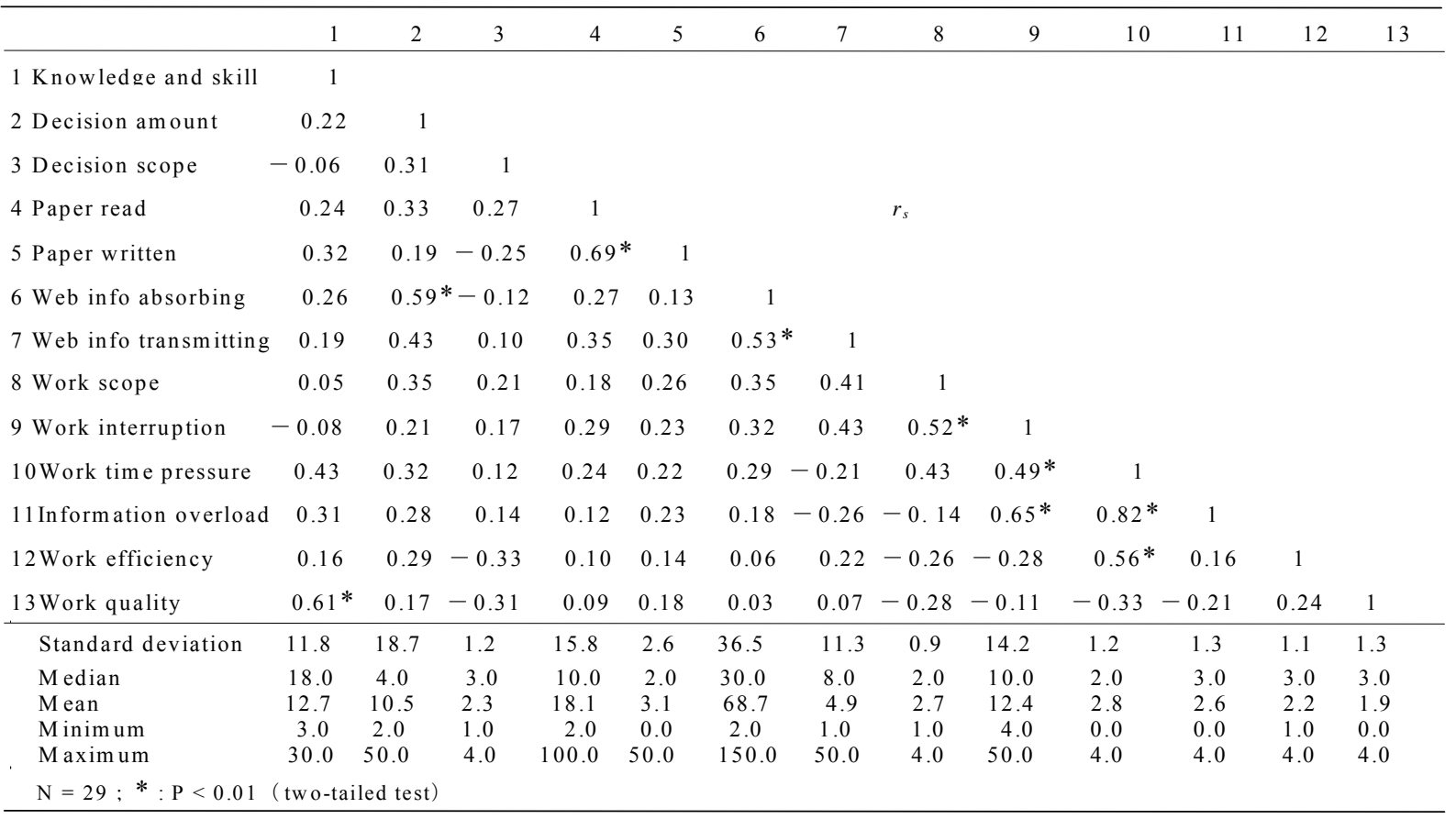


some previous investigation around which this research was carried out [12]. Our results have shown no significant correlation between information overload with work efficiency and work quality. That is to say, our investigation data supports the conclusion that there is no obvious relationship between information overload and the efficiency or quality of works. As for the cause of information mainly comes from the work time pressure which lead to people perceptual information overload. The second cause of information overload perhaps comes from work interruptions. The amount of information could not give rise to information overload individually. And therefore, it should be considered within a time frame when the researcher investigates and analyses the information phenomena.

The results in this paper maybe help us to understand that there are adjustability and complexity in human adoption in confronting more information amount which can change according the human learning capacity, working team and work scope. Reasonable information overload is not necessarily unhelpful to most tasks. In some context, information overload will not definitely decrease work performance, but in the other way round, increase it. The findings above offer the basis for a new framework to understand the information overload phenomenon. This research provides the findings base on study data collected from a relatively small sample base. Thus, a suggestion for future research is to simple increase the size of sample of individuals researched.

\section{REFERENCES}

[1] A. Toffler, "Future Shock," Random House, New York, 1970.

[2] O. E. Klapp, "Overload and Boredom," Greenwood Publishing Group Inc., Westport, Greenwood, 1986.

[3] R. S. Wurman, "Information Anxiety 2," Macmillan Pub- lishing, Indiana, 2001.

[4] A. G. Schick, L. A. Gordon and S. Haka, "Information Overload: A Temporal Approach," Accounting Organizations and Society, Vol. 15, No. 3, 1990, pp. 199-220. doi:10.1016/0361-3682(90)90005-F

[5] D. Bawden, C. Holtham and N. C. Courtney, "Perspectives on Information Overload," ASLIB Proceedings, Vol. 51, No. 8, 1999, pp. 249-255. doi:10.1108/EUM0000000006984

[6] C. J. Casey, "Coping with Information Overload: The Need for Empirical Research," Cost and Management, Vol. 66, No. 4, 1992, pp. 31-38.

[7] S. C. Schneider, "Information Overload: Causes and Consequences," Human Systems Management, Vol. 7, No. 2, 1987, pp. 143-154.

[8] M. R. Swain and S. F. Haka, "Effects of Information Load on Capital Budgeting Decisions," Behavioral Research in Accounting, Vol. 12, 2008, pp. 171-199.

[9] R. Glazer, "Locally Rational Decision Making: The Distracting Effect of Information on Managerial Performance," Management Science, Vol. 38, No. 2, 1992, pp. 212-227. doi: $10.1287 / \mathrm{mnsc} .38 .2 .212$

[10] K. Kiley, "The Cyberspace Database Information Overload," Catalog Age, Vol. 12, No. 9, 2005, pp. 56-59.

[11] C. E. Meglio and B. H. Kleiner, "Managing Information Overload," Industrial Management and Data System, Vol. 1, No. 1, 1990, pp. 23-26. doi: $10.1108 / 02635579010003405$

[12] G. Wheelight, "Information Overload," Communications International, Vol. 22, No. 1, 1995, pp. 55-58. 